\section{Endoscopic ultrasound-guided therapy of a rectal Dieulafoy lesion}

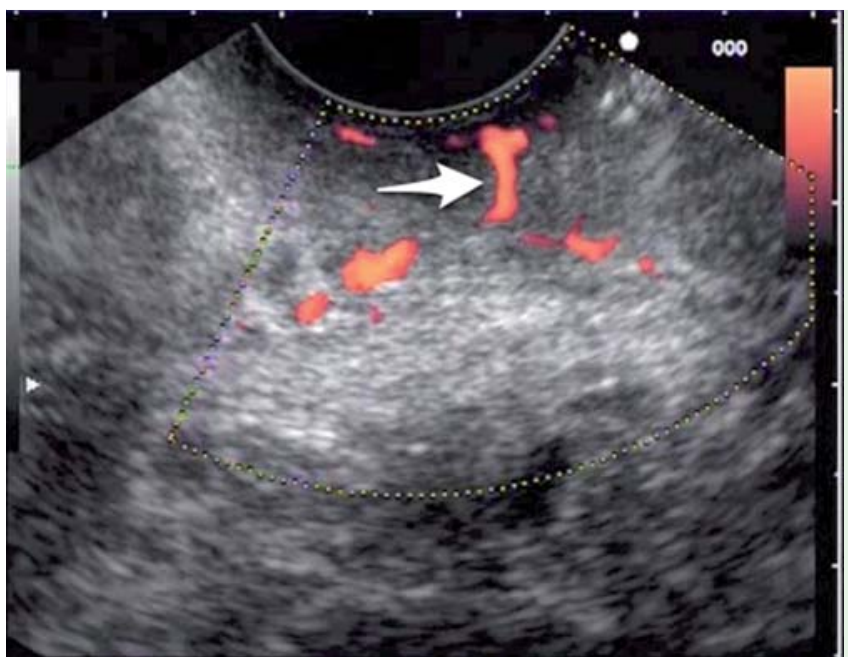

Fig. 1 Endoscopic view in a 68-year-old man with stage IV renal cell adenocarcinoma and lower gastrointestinal bleeding: a widecaliber vessel (arrow) is seen coursing from the perirectal fat tissue entering the rectal wall and reaching the mucosal surface without tapering. This finding is consistent with a rectal Dieulafoy lesion and this area corresponded to the site of bleeding.
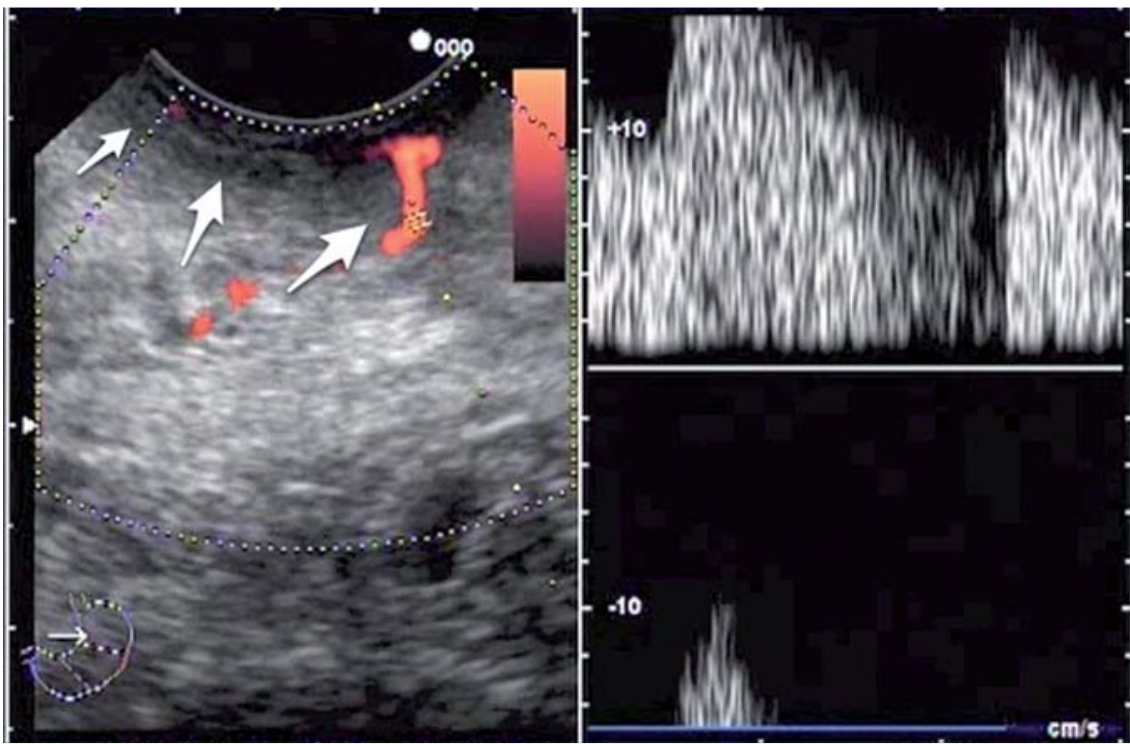

Fig. 2 Pulsed Doppler study showing arterial flow into the vessel, confirming the provisional diagnosis. The white arrows are pointing towards the muscularis propria of the rectal wall. The arterial vessel is clearly seen entering the rectal wall through the muscularis propria.

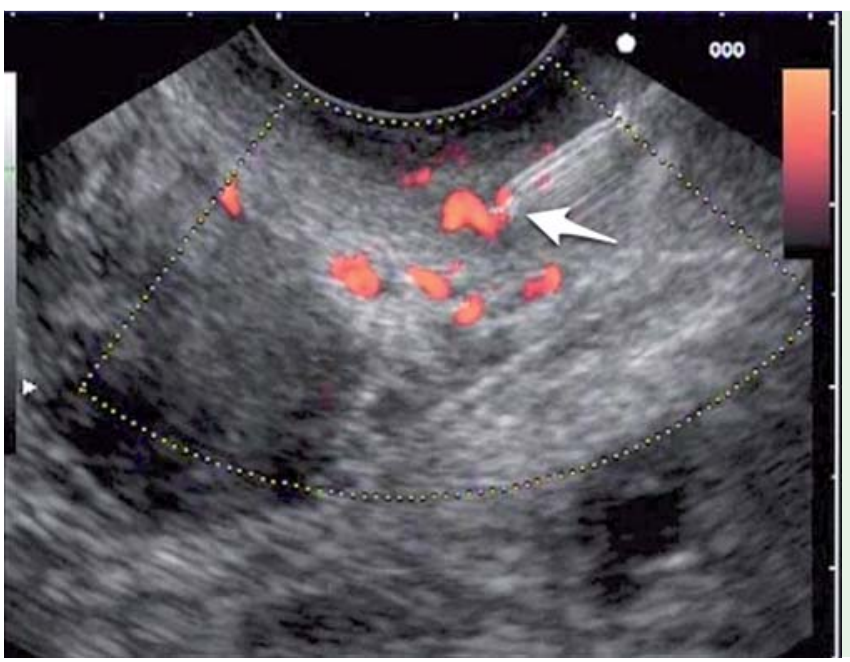

A 68-year-old man with stage IV renal cell adenocarcinoma was admitted for severe lower gastrointestinal bleeding and hemodynamic instability. After blood transfusion, colonoscopy revealed fresh blood in the rectum and sigmoid colon but no apparent lesions. At 4 days after admission, the patient experienced another episode of severe bleeding. A repeat colonoscopy showed active pulsatile bleeding from an exposed vessel without mucosal ulceration, consistent with a Dieulafoy lesion located $3 \mathrm{~cm}$ above the anal verge. An endoscopically administered epinephrine injection $(1: 10000)$ stopped the bleeding. After 5 days, recurrence of bleeding was noted from the treated vessel but it ceased with appropriate placement of two hemoclips and another epinephrine injection. However, in spite of this endoscopic treatment, 4 days later the patient had re-bleeding. Endoscopic ultrasound (EUS)-guided vascular treatment was planned prior to considering surgical treatment ( $\bullet$ Video 1$)$. The ultrasonographic view showed a persistently widecaliber vessel, that is, without any sign of tapering, coursing directly toward the mucosal surface ( $\boldsymbol{Q}$ Fig. $\mathbf{1})$ with arterial flow ( Fig.2). Under EUS guidance, the rectal wall was punctured the needle tip directed toward the vessel ( $\bullet$ Fig. 3 ) and $6 \mathrm{~mL}$ of $2 \%$ polidocanol was injected, with cessation of bleeding ( Fig.4). Subsequently, the patient did not experience any new bleeding episodes and was discharged, however, 2 months later he passed away following progression of his oncologic disease.

Endoscopic treatment of bleeding Dieulafoy lesions, with epinephrine injection or hemoclips, should be attempted before considering surgery $[1,2]$. Successful EUS-guided treatment has been described for gastric [3] and duodenal [4] Dieulafoy lesions but to our knowledge it has never been reported for rectal lesions. In this setting, EUS allowed accurate identification of the source of bleeding and precise delivery of the thrombotic agent into the target vessel. This treatment offers a new option for minimally invasive treatment before surgery [4].

\section{Video 1}

The submucosal wide-caliber vessel is seen reaching the mucosal surface. After confirmation of arterial flow in the vessel, endoscopic ultrasound (EUS)-guided injection of $2 \%$ polidocanol was carried out with disappearance of the Doppler signal. 


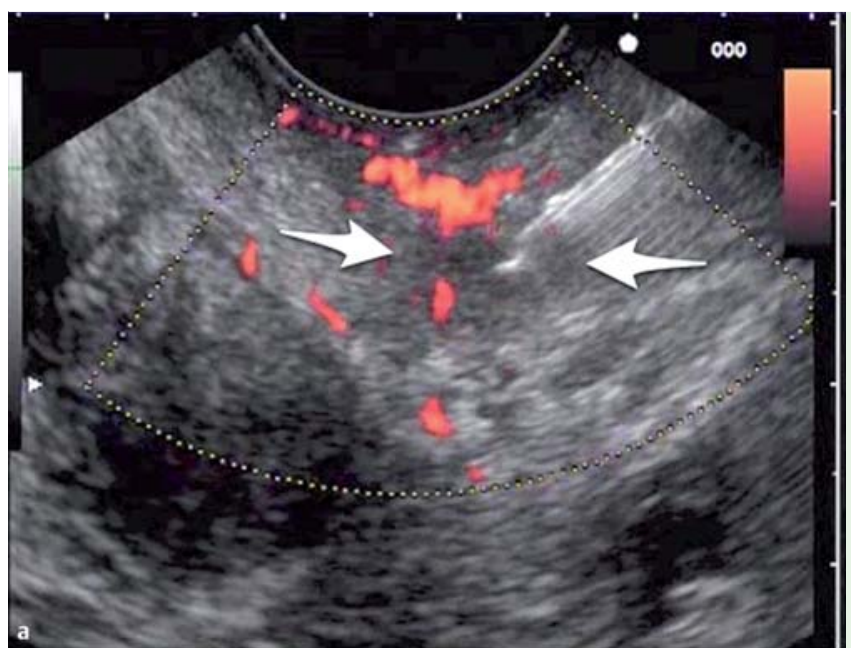

Fig. 4 a Polidocanol $2 \%$ was injected, creating a submucosal cushion (the area between the two arrows).

b The submucosal cushion (arrows) has increased in size following completion of the injection with disappearance of the Doppler signal in the vessel.

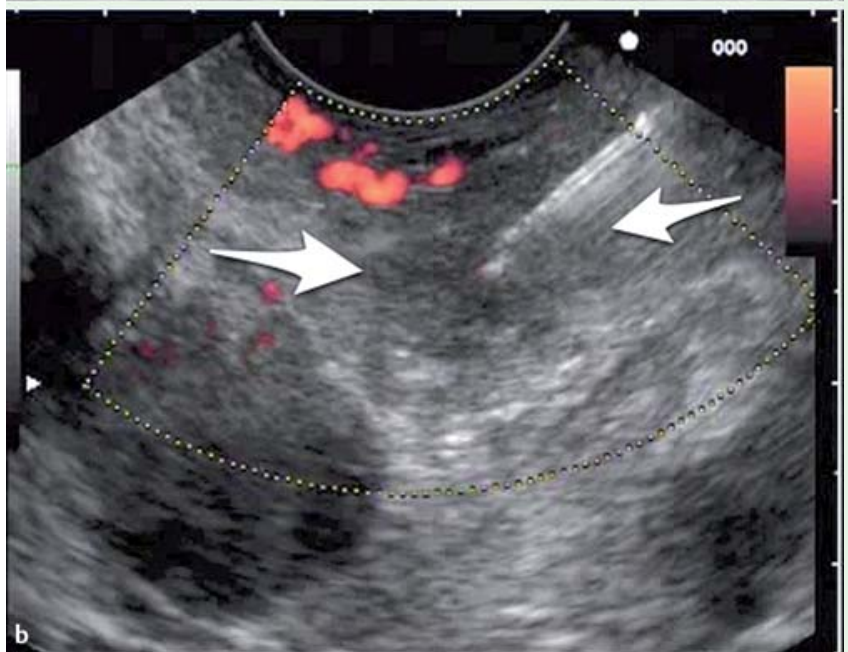

Endoscopy_UCTN_Code_TTT_1AS_2AZ

\section{Competing interests: None}

\section{J. J. Vila ${ }^{1}$, M. Pérez-Miranda ${ }^{2}$, M. Basterra ${ }^{1}$, M. Gómez ${ }^{1}$, \\ I. Fernández-Urién ${ }^{1}$, F. J. Jiménez ${ }^{1}$}

${ }^{1}$ Endoscopy Unit, Department of Gastroenterology, Complejo Hospitalario de Navarra, Pamplona, Spain

2 Endoscopy Unit, Department of Gastroenterology, Hospital Río Hortega, Valladolid, Spain

\section{References}

1 Dulic-Lakovic E, Dulic M, Hubner D et al. Bleeding Dieulafoy lesions of the small bowel: a systematic study on the epidemiology and efficacy of enteroscopic treatment. Gastrointest Endosc 2011; 74: 573-580

$2 \mathrm{Kim} \mathrm{HH,} \mathrm{Kim} \mathrm{JH,} \mathrm{Kim} \mathrm{SE} \mathrm{et} \mathrm{al.} \mathrm{Rectal} \mathrm{dieula-}$ foy lesion managed by hemostatic clips. J Clin Med Res 2012; 4: 439-441

3 Gonzalez JM, Giacino C, Pioche M et al. Endoscopic ultrasound-guided vascular therapy: is it safe and effective? Endoscopy 2012; 44: $539-542$

4 Levy MJ, Wong Kee Song LM, Farnell MB et al. Endoscopic ultrasound (EUS)-guided angiotherapy of refractory gastrointestinal bleeding. Am J Gastroenterol 2008; 103: $352-$ 359

\section{Bibliography}

DOI http://dx.doi.org/

10.1055/s-0033-1344776

Endoscopy 2014; 46: E84-E85

(c) Georg Thieme Verlag KG

Stuttgart · New York

ISSN 0013-726X

\section{Corresponding author}

\section{J. J. Vila}

Endoscopy Unit, Gastroenterology Dpt

Complejo Hospitalario de Navarra

C| Irunlarrea 3, 31.008

Pamplona

Spain

Fax: +34-848-422303

juanjvila@gmail.com 